\title{
Rational Choice Theory: Toward a Psychological, Social, and Material Contextualization of Human Choice Behavior
}

\author{
Tom Burns ${ }^{1,2}$, Ewa Roszkowska ${ }^{3}$ \\ ${ }^{1}$ Department of Sociology, University of Uppsala, Uppsala, Sweden \\ ${ }^{2}$ Lisbon University Institute/CIES-ISCTE, Lisbon, Portugal \\ ${ }^{3}$ Faculty of Economy and Management, University of Bialystok, Bialystok, Poland \\ Email:tom.burns@soc.uu.se,erosz@o2.pl
}

Received 4 March 2016; accepted 11 April 2016; published 14 April 2016

Copyright (C) 2016 by authors and Scientific Research Publishing Inc.

This work is licensed under the Creative Commons Attribution International License (CC BY). http://creativecommons.org/licenses/by/4.0/

c) (i) Open Access

\section{Abstract}

The main purpose of this paper is to provide a brief overview of the rational choice approach, followed by an identification of several of the major criticisms of RCT and its conceptual and empirical limitations. It goes on to present a few key initiatives to develop alternative, more realistic approaches which transcend some of the limitations of Rational Choice Theory (RCT). Finally, the article presents a few concluding reflections and a table comparing similarities and differences between the mainstream RCT and some of the initial components of an emerging choice theory. Our method has been to conduct a brief selective review of rational choice theoretical formulations and applications as well as a review of diverse critical literature in the social sciences where rational choice has been systematically criticized. We have focused on a number of leading contributors (among others, several Nobel Prize Recipients in economics, who have addressed rational choice issues). So this article makes no claim for completeness. The review maps a few key concepts and assumptions underpinning the conceptual model and empirical applications of RCT. It reviews also a range of critical arguments and evidence of limitations. It identifies selected emerging concepts and theoretical revisions and adaptations to choice theory and what they entail. The results obtained, based on our literature reviews and analyses, are the identification of several major limitations of RCT as well as selected modifications and adaptations of choice theory which overcome or promise to overcome some of the RCT limitations. Thus, the article with Table 1 in hand provides a point of departure for follow-up systematic reviews and more precise questions for future theory development. The criticisms and adaptations of RCT have contributed to greater realism, empirical relevance, and increased moral considerations. The developments entail, among other things: the now well-known cognitive limitations ("bounded rationality") and, for instance, the role of satisficing rather than maximizing in decision-making to deal with cognitive 
complexity and the uncertainties of multiple values; choice situations are re-contextualized with psychology, sociology, economic, and material conditions and factors which are taken into account explicitly and insightfully in empirical and theoretical work. Part of the contextualization concerns the place of multiple values, role and norm contradictions, and moral dilemmas in much choice behavior. In conclusion, the article suggests that the adaptations and modifications made in choice theory have led to substantial fragmentation of choice theory and as of yet no integrated approach has appeared to simply displace RCT.

\title{
Keywords
}

\author{
Rational Choice Theory, Cognitive Revisions, Psychological, Social, and Material Embeddedness, \\ Moral Agency, Theory Fragmentation
}

\section{Introduction}

The rational choice approach, of which classical game theory is a variant, has been until recently the dominant approach for conceptualizing human action in the social sciences. This theory is focused on a few determinants of individual choices; and methods of aggregating social behavior are based on the decisions of individual actors. The concept of rationality is widely used in economics models, where the individuals are also referred as homo oeconomicus which means that that they are rational and self-interested.

Certainly, this theoretical approach could claim the most systematic and elegant formulations of human action models. Rational choice is concerned, generally speaking, in finding the best means to given ends; more specifically, in the face of a decision-making situation, an actor considers a finite set of alternatives, ascribes consequences to them, orders these consequences according to their importance and value, and makes an optimal choice among available alternatives. The actor is assumed to know all available alternatives, and chooses the best action or means to achieve her ends on the basis of expectations about future consequences or outcomes of her choices.

Also, it has had a wide range of applications: among others, operations research, decision engineering, game theory, foundations of microeconomic theory, enterprise decisions about production, output, investment, and technological change, personal choices about marriage, child-bearing, crime, education; personal and household choices about consumption and savings, public policy and public choice, group and organizational behavior in sociology; and criminology, deterrence theory, and international relations. The same basic structure of rational choice underlies modem game theory, decision engineering operations research, and the various analytical approaches to improving choices and information systems, in the blending of aviation fuel, the location of warehouses, the choice of energy alternatives, and the arrangement of bank queues, as well as many other decision problems.

Below we provide a brief overview of the rational choice approach, followed by an identification of several key criticisms and limitations. The most common argument against the use of rational choice models outside economics and society is that they make unrealistic assumptions about individual behavior as well as the structure of the situation. A common main criticism is that real decision-makers are not strict rationally calculating and self-interested. They are constrained by institutions, cultural influences, and psychological limitations that make the assumption of rationality problematic at best, and foolhardy at worst. Finally, we identify attempts to develop alternative, more realistic approaches which transcend some of the limitations of RCT.

The structure of the paper is as follows. We start by presenting basic assumptions of Rational Choice Theory in Section 2. In Section 3 we discuss the main limitation RCT. Section 4 will examine several extensions of RCT that have been made in an effort to transcend some of its limitations.

\section{Rational Choice Theory: Basic Assumptions and Approach to Human Social Action $^{1}$}

Rational choice is formulated in universalistic terms, abstracted to a large extent from historical and socio-

\footnotetext{
${ }^{1}$ Among the scholars in the social sciences, especially economics, who have contributed to the development of RCT are: [1]-[16].
} 
cultural context. A fundamental premise is that each actor pursues his or her personal values and self-interest, typically in the context of-and against-others rationally pursuing their own self-interest and their private values. Such theory emphasizes the volitional nature of human action and the capability of actors to make decisions and to act on the basis of rational calculations of benefit and cost. Individual actors are assumed to be more or less fully informed about their action situations and to choose the best action or means to achieve their ends.

Rational choice theories - they are multiple with several variants — have the following components:

1) an actor or collective agent in a decision situation identifies or specifies alternative actions or sequences of actions, her repertoire of options in the decision situation, that are possible (permitted) and are known unambiguously;

2) she determines the consequences resulting from each of the alternatives, the possible outcomes or payoffs of the options, that is the actor is assumed to know all relevant consequences of her alternative actions;

3) the actor has preferences among the options, with what is assumed to be a consistent preference ordering; this assumes moreover that the consequences of acts can be compared in terms of subjective preferences or utilities; effectively, there is comparability of the values or preferences of each of the sets of consequences;

4) the actor applies a decision or choice procedure to the alternatives to determine which maximizes net gain; the procedure selects a single alternative on the basis of its consequences for the actor in terms of her preferences or utilities. More precisely, the actor makes a choice by selecting the alternative which maximizes a utility or value function.

In sum, rational choice action is caused (motivated) by the (self-)interest of the individual oriented to the consequences as she perceives or defines them. The actor judges/distinguishes the costs and benefits of alternative actions (their consequences or outcomes), with concern solely about the consequences for herself (although some variants of RCT have relaxed this assumption). He or she chooses the alternative with the most net gain or "utility" (In more rigorous formulations, one uses algorithms to model actor decisions which maximize (or optimize within defined constraints) with respect some to a utility function). An event, action, social process or institution can thus be explained in terms of the rational choices of individual agents; then and only then we say it has been analytically "explained” [3].

\section{Criticism and Limitations}

The cumulative critique of rational choice theory has been massive and its summary would require a book. ${ }^{2}$ We have chosen to focus on a few key limitations that are both theoretical and empirical in character:

1) the asocial individual, or the individual decision-maker separate from society;

2) unrealistic cognitive and psychological assumptions, for instance complete information or super-calculability capabilities;

3) agency lack innovative or creative capabilities;

4) lack of a moral dimension, that is, the amoral agent.

\subsection{The Atomistic, Super-Rational Individual Outside of Society}

In general, the approach assumes that individuals as rational actors are defined prior to, or in a certain sense outside of, the social system or situation in which they act ([17]). Society per se does not exist, or it is only continually emerging spontaneously. The premise of rational choice theory as a social science methodology is that the aggregate behavior in society reflects the sum of the choices made by individuals. Moreover, the theory makes two main assumptions about individuals' preferences over alternatives: completeness and transitivity, which follows that given a set of actions to choose from, an individual can rank the elements of this set in terms of her preferences constitutes a partial ordering and the set has at least one maximal element. Such a concept of rational behavior says nothing about belief or what rationality implies when agents do not know with certainty everything relevant to their choices and leaves them with incomplete preferences, with which they are not assumed to be able to deal. At the same time, some experiments show that people's preferences are not in fact transitive and they act "irrationally" in their choices. For example, in the case of so-called "preference reversals" in response to ambiguity aversion, it seems plausible that people in fact are inclined to make irrational choices ([22] [24]). Also, rational choice is improperly extended to circumstances characterized by uncertainty-where

\footnotetext{
${ }^{2}$ See, among many others: [1] [4] [5] [13] [16]-[32].
} 
the agents do not know the probabilities or even all the possible outcomes of their choices (hence, risk assumptions and calculations do not apply). Also problematic is the condition of independence which means the preferences of rational agent between two lotteries that differ in only one outcome should match their preferences between the two possible sets of outcomes. Although initially plausible, the independence condition is very dubious in many choice situations (see [33]).

When an agent's preferences are complete and transitive and satisfy a continuity condition, then they can be represented by a so-called ordinal utility function. If an in addition independence condition some other technical conditions are satisfied, then they can be represented by an expected utility function ([19]). But the technical requirements lead further and further away from real conditions of behavior and away from useful applicability.

Rational choice agents operate outside of social systems. The agents are social atoms, rationally calculating to further their own self-interests, wholly free from social encumbrances and cultural constraints. This is in contrast to social embeddness approaches to human action, as discussed below. There is overwhelming evidence that factors other than self-interest such as concern for others in interpersonal relations, institutionalized roles, values and culture generally are central to much human judgment and action ([16] [26] [34]-[36]). RCT provides little insight and explanation about much social behavior (indeed, it was never designed to do so), since humans as social beings are embedded in social relations and institutional and socio-cultural arrangements of family, work, and community.

Among the major limitations, the RCT cannot directly and efficiently explain such phenomena as ([16] [17] [20] [34] [35] [37]):

1) collective action, the co-operation of individuals in groups, associations, and other forms of joint action, where individuals choose something which benefit others more than themselves;

2) that often people adhere to and follow to social norms over time and space such as for instance altruism, reciprocity, and trust, even if such behavior visolates their self-interest;

3) social structural phenomena not reducible to the actions of particular individuals, require explanation in terms other than agent choices (e.g., socio-cultural evolution, or material or ecological patterns).

\subsection{Complete Information, Little or No Cultural or Institutional Knowledge}

The RCT actor is assumed to have full knowledge of her own situation, her action alternatives, and payoff functions. This is far more factual knowledge about action alternatives and game consequences than is usually realistic; actors are often quite ignorant about their action possibilities and possible outcomes. On the other hand, social science research indicates that that social actors typically have substantial normative, moral, and practical knowledge which they employ in making judgments and acting, and in interpreting and understanding, as well as criticizing, others' behavior. Giddens [38] refers to the extraordinary knowledge of human actors, especially about their roles, relationships, and institutional conditions. Analysis of such cultural knowledge, and an understanding of its role in human action and interaction is essential to interaction analysis but lies outside the scope of RCT.

\subsection{The Impossible Calculating Agent}

The actor in RCT is assumed to have fully ordered and consistent preferences, which are stable over time and space. She also is supposed to have unlimited calculating capabilities enabling her to deal with all the information that complete knowledge implies and to process that information in mathematically consistent and effective ways so as to make decisions. Very substantial social science research indicates that social agents' preferences are often not clearly or consistently ordered and may be highly variant over time, space, and social context. Actors' capabilities to reason consistently and to make calculations on the basis of complex information and multiple objectives are much more limited than conventional RCT assumes.

Some limitations of RCT derived from the relatively unrealistic cognitive and social psychological assumptions of the theory and from weak applicability and empirical relevance of the theory to the analysis of concrete social phenomena. For instance, a number of established empirical results regarding judgment and choice falsify rationality assumptions ([22] [24]). In general, Rational Choice Theory has been particularly challenged by the experimental results of behavioral economics (see discussion later of the work of Kahneman and Tversky [22] and Thaler and Sunstein [39]. 


\subsection{Lack of Genuine Agency. Rather a Robotic Agency Agent ${ }^{3}$}

A major problem with the RCT approach is that it consists, on the one hand, in the very simplistic behavioral model assumed and, on the other, the drastically artificial assumptions which have to be made for such a model to be made "operational". Indeed, the optimization process, given the information (perfect or less than perfect) that the individual has about his or her "given environment" and about his "feasible set of options," becomes in a certain sense a simple exercise in calculus.

The RCT conceptualization of human action allows very little behavioral freedom to individuals and social agents. The "freedom" they possess is more in deciding their objectives, what and how they value things. But it is precisely these matters that are left unexplained by the theory: "Tastes and preferences" are given, or simply assumed. If, on the contrary, a much broader scope is allowed the rational-choice approach, it turns out saying something to the effect that everyone seeks to satisfy his or her own interests even if these include tastes for altruism and solidarity rather than self-interest. But such a theoretical proposition is so general that it is deprived of any operational meaning, even its context free basic assumption. It does not answer the prior question of why people have certain preferences rather than others.

Actors are assumed to engage in social processes programmed a priori to behave according to the universal rule of rational, utilitarian calculation. RC theories (and also game theory) lack a notion of the creative/destructive/transformative agent who, among other things, may deviate from some of the rules of action and, indeed, in some instances transform the situation into one with new conditions, new action opportunities, payoffs, and motivational complexes.

\subsection{Universal Decontextualization 4}

Rational choice theory (and game theory) formulates a principle of choice-the maximization of utility - that is applied universally, abstracting from all cultural and social contexts, civilizations, historical epochs, cultural forms, institutional spheres, social relationships etc. From the perspective of an empirical social science, this is a serious limitation. One observes that the choice principles or patterns as well as evaluative rules underlying preference structures vary systematically as a function of social relationships and institutional and cultural context. Social beings have the capability to use a variety of choice procedures, depending on the context in which they find themselves. One generally does not judge and decide in the same way — on the same terms —in a family or friendship network as in an employer-employee setting, an administrative, or a market setting ([4] [5]).

\subsection{Lack of Moral Orientation}

In RCT norms and ethical considerations are not part of the conception of the human actor. The individual has subjectively based "self-interest” and concerns herself only with consequences for herself. Questions of ethics or of moral sentiments are not of conceptual interest. In any case, such sentiments would simply be understood as “incorporated” into actors' preferences, and not part of a multi-value socially shared complex. In general, matters of morality and ethical behavior have to be raised and analyzed outside the theory ([19]). Yet, human beings are moral beings, or aspire to be so [5].

Moral sentiments enter into actors' judgment and action processes. Actors' relationships engender notions of fairness and justice, e.g., principles of distributive justice. Their roles function as sources of moral obligation: to obey or to resist; to cooperate or to refuse to cooperate; to help or to expect help (for example, in the latter case, members of a voluntary organization or church group are expected to help specific categories of persons (the poor, homeless, mentally disturbed) but not others (communists, rival religious communities)).

In general, actors are to a greater or lesser extent motivated by-and their judgments and actions biased bymoral and ethical aspects of their relationships with others. Utilitarian or instrumental aspects are not unimportant. Indeed, they themselves are often normatively indicated, as in market, technical, or other instrumental settings. Moreover, such considerations find their place in all cultural frames. But these aspects of human action must be seen as a part of a complex, multidimensional rationality of human judgment and action, not the only or the main basis for formulating, as in RCT, a universal model of uni-dimensional human agency.

For these as well as other reasons, RCT, in spite of its many valuable contributions to social science, is simply

\footnotetext{
${ }^{3}$ See, among many others ([17] [38]).

${ }^{4}$ See, among many others ([4] [5] [36]).
} 
unable to take into account or analyze, at least in any systematic way, the social and moral bases of preference structures, action alternatives, decision principles and human action (and interaction) patterns. At the same time it fails to conceptualize and explain how and why human agents shape and reshape their social conditions as part of the historical development of social institutions and societies. Unfortunately, these and related matters are not taken into account in the rational choice program in the conventional choice perspective.

\section{Adaptive and Alternative Developments}

\subsection{Overcoming Conceptual and Empirical Limitations of Rational Choice Theory}

Conventional RCT models have had a limited and unreliable degree of empirical success, that is, they have only contributed to a limited degree to the overall understanding of social action, whether economic, political, religious, interpersonal ([9] [16] [18] [19] [22] [24] [39]). And one of the main reasons for the multiple theoretical initiatives with assumptions and formulations differing from core RCT has been the desire to increase empirical leverage, in response to RCT's failure to develop a robust empirical research program. Harsanyi [19], the Nobel Prize Winner in Economics (1994), has pointed out, along with many others, that... individual decision theory of which game theory is a generalization should be regarded as a purely formal theory lacking empirical content. Both decision theory and game theory state merely what will happen, if all participants have consistent preferences, and actually follow their own interests as defined by their preferences, in a fully consistent and efficient manner.

While RCT has been arguably criticized most for its extremely unrealistic assumptions about human agency, its major scientific failure derives from its empirical failings among others:

- The fact that social norms, networks, institutional arrangements, socialization processes profoundly influence how individuals act and interact, shaping and regulating their preferences, beliefs, action repertoires (“opportunity structures”) and patterns of behavior;

- People's behavior is influenced in many instances, of course, by payoffs or outcomes but also by how situations and problems are framed, the moral meanings and discourses associated with their roles and relationships;

- People adhere to norms of reciprocity, justice, altruism in the absence of unambiguous net gains for their behavior;

- People are highly constrained by their roles, institutions, and cultural forms so as to behave in what appear to be "non-rational" ways.

And one of the main reasons for the multiple theoretical initiatives with assumptions and formulations differing from RCT is the desire to increase empirical leverage, in response to its failure to develop a robust empirical research program, as suggested above.

\subsection{Cognitive Modification of Rational Choice Theory}

H. A. Simon, Nobel Prize winner in economics (1978) relaxed assumptions of rational choice theory (in particular utility theory) when he coined the phrase "bounded rationality" taking into account the cognitive, knowledge, and computational limitations of decision-makers. The concept of "bounded rationality" takes into account the cognitive and knowledge limitations of decision-makers. Thus, Simon relaxed assumptions of rational choice theory (in particular utility theory). He also stressed that typically decision-makers operate with multiple values, a vector of values, where one could not assume commensurability of values, and the reduction of values and the reduction of multiple values to a common metric ([40]). He also stressed the role of decision procedures/ algorithms to deal with complexity and dilemmas as well as uncertainty, thus, challenging the maximization principles.

In his re-conceptualization of human thinking and decision making, ${ }^{5}$ Simon pointed out that rational behavior is constrained not only by the limited informational and computational capabilities of human beings but the cost of obtaining information. Instead of maximizing their welfare, profits, or utility, actors behave "rationally” by

\footnotetext{
${ }^{5}$ Simon envisioned his conception of "approximate" rationality as providing "some materials for the construction of a theory of the behavior of a human individual or of groups of individuals who are making decisions in an organizational context” [30]. Moreover, "The aim of this chapter has been to construct definitions of "rational choice" that are modeled more closely upon the actual decisions processes in the behavior of organisms than definitions heretofore proposed. I have outlined a fairly complete model for the static case and have described one extension of this model into dynamics” [30].
} 
"satisficing" given real world circumstances; they do this because of a lack of situational information (incomplete knowledge) about alternatives and the impossibility of foreseeing the future, He coined the term "satisficing" as a counter-position to maximizing or optimizing — and stressed that we often accept non-maximal or non-optimal states because we don't have sufficient knowledge about other alternatives in the situation, or because we do not have the time and resources to find better results. But he saw satisficing as a way to deal with multiple incommensurable values, not simply a cognitive limitation.

Kahneman and Tversky [22]; also Kahneman et al. [24] continued the exploration and development of the cognitive aspects of judgment and choice, bringing new concepts and analyses to rational choice challenges (Kahneman received the Nobel Prize in Economics in 2002). Like Simon, Kahneman and Tversky saw judgment/decision-making as a process. "Framing" of the choice situation and "reference points" in a cognitive space were critical concepts in their "prospect theory." Prospect theory predicts that judgments and preferences depend on how situations are framed. Framing brings in reference points, categories, aspiration levels, and preferences, of course. Once the situation is "appropriately" framed, then actors will cognitively figure out what are the concrete conditions of choice, how these are to be understood, what are their meaning(s), and what is it that she wants or wants to accomplish in the situation.

According to Kahneman and Tversky's prospect theory [22], people evaluate gains or losses from a status quo, an assumption consistent with adaptation-level findings that occur not just in perception but in virtually all experience. That is, actors adopt to a constant level of a psychological dimension and establish it as neutral. The key derivation is that whether one frames a choice as a gain or a loss or a "mixed" one, it makes a significant difference in actors' ultimate judgments and behavior.

Another cognitive based approach to decision-making ("nudge theory") emerged in 2008 ([39]). It considered how people's perceptions are altered through framing, changing the choice architecture. Nudge is any aspect of the choice architecture that alters people's behavior in a predictable way without forbidding any options or significantly changing their economic incentives. To count as a mere nudge, the intervention must be easy and cheap to avoid. One of nudges' most frequently cited examples is the etching of the image of a housefly into the men's room urinals at Amsterdam's Schiphol Airport, which is intended to "improve the aim". Nudges are not mandates.

\subsection{Procedural and Algorithmic Concepts}

Simon's early choice papers—and also in the larger body of his work—-he stressed procedures or algorithms for pursuing, for instance, particular goals and complexes of goals [30]. He contrasted some of his "simplified" rules and procedures with those of what he referred to as "global" models of rationality (see, for example, [30]. Even in his characterization of "classical theory" [30] he refers to "procedures" of rational choice: "max-min rule," "probabilistic rule," and "certainty rule.” Implicitly, as his examples of satisficing indicate, human beings operate with such diverse procedures or algorithms (and not a universal maximization principle). The challenge, as he saw it, is to formulate procedures that approximate what people actually do, e.g., in his satisficing procedure [30]. An example of the type of procedure or algorithm Simon had in mind is that of the "Max-Min Rule," but much more complex algorithms can be constructed, for example, in complex judgments and choice situations [30].

\subsection{Psychological, Social, and Material Embeddedness of Choice}

Burns et al. [17], Burns and Roszkowska [40], Elster [34] [35] [41], Harre [42], Granovetter [36], and Hodgson [43] [44], among others, in their critiques of the basic concept of the abstract, super-rational anomic individual of rational choice, point toward a perspective where human actors are genuinely social and human. The social situation and constraints and possibilities - within which actors make decisions or play out games are defined by a prior, given culture, social structure, social relations and norms. Certainly, a basic truth of modem science is that social activity does not take place prior to or outside of social structure. At the same time, social agents may modify or transform social structures or create entirely new structures, but they do this within given social and material conditions.

This "social embeddedness" of human agents ([36]) implies then culturally or relationally specific rationalities (specified in value orientations, judgment systems, and action strategies). The rationalities are defined by the roles and role relationship(s) of participating actors. A given role relationship entails certain category and de- 
scriptive rules, evaluative, and decision as well as action rules (including institutionalized procedures and rituals).

For instance, outcomes are evaluated — and preference structures generated-by the actors on the basis of evaluative rules defined within their social relationships. A socially contextualized decisions (or interactions in a game) have a certain social logic or rationality and context specific equilibria, if these exist. Likely patterns can be predicted on the basis of actors' culturally based conceptions of, and the rule regimes applying in, their action situation (with its specific cultural and institutional forms and history) and its categorization and framing of the situation with particular distinctions, action possibilities and outcomes. Earlier work ([10] [12] [17] [36] [40] [45]) have shown how people's social relationships and institutional conditions frame their models (beliefs, perceptions), value complexes and evaluations, judgments and decisions, and patterns of interaction.

The concept of the social embeddedness of, for instance, choice situations (and games) leads one to look for relationally specific and role based preference structures, decision procedures, and normative rules that shape and guide actors' behavior vis-a-vis one another. Although Simon as well as Tversky and Kahneman made occasional references to "norms" and the social situation, neither of the approaches particularly recognized or stressed the normative conditions of most judgments and choices. Social institutional and role concepts as well as "sacrality" and human passions were basically alien ideas (although Simon [32] wrote an important paper on emotions and choice; see also [23]).

The concept of social embeddedness implies that context-dependent rationality, choice and interaction, including strategic types of action, are defined, constituted and regulated on the basis of social relationships among actors and the cultural and institutional frame in which the interactions take place. Institutional arrangements, organizing principles, cultural forms, social roles, and rules of conduct shape and regulate what actors tend to do, or to avoid doing. The social roles and rules, e.g., decision rules, prevailing within neighborhoods or community organizations differ significantly from those within markets or bureaucratic organizations. The specific evaluation and action rules that friends or kinsmen are predisposed to use vis-a-vis one another in relevant interaction settings differ significantly from those likely to be used by actors with other types of social relationships, such as competitive or adversary relations. Moreover, agents through their entrepreneurship, their creative/destructive actions change their social context, the very qualities and conditions of their embeddedness.

In sum, human action is conceptualized and analyzed as socially embedded. The concept of social embeddedness implies that context-dependent rationality, choice and interaction, including strategic types of action, are defined, constituted and regulated on the basis of social relationships among actors and the cultural and institutional context in which the interactions take place. Institutional arrangements, organizing principles, cultural forms, social roles, and rules of conduct shape and regulate what actors tend to do, or not to do. The social roles and rules, e.g., decision rules, prevailing within neighborhoods or community organizations differ significantly from those within markets or bureaucratic organizations. The specific evaluation and action rules that friends or kinsmen are predisposed to use vis-a-vis one another in relevant interaction settings differ significantly from those likely to be used by actors with other types of social relationships, such as competitive or adversary relations.

Contextualization not only refers to social embeddedness but to actors' involvement in the material world: where, when and how they make choices and act. Particular resources, tools, and technologies are framed, mobilized, and utilized in actors' behavior, including innovative initiatives and projects. Many choices cannot be made or realized without the availability of particular essential materials and technologies that need to be applied in the action processes. For instance, in the case of Leonardo da Vinci's many designs and inventions, there was a lack not only of some essential knowledge (cognitive limitatioins) but essential resources and technologies for their realization. The realization of many of them had to wait several hundred years ([46]).

In other words, there is a resource base to choice behavior and its realization - thus, entailing the materiality aspects of context. A decision-making actor's resource base consists of materials, tools, technologies, built environments (building, stadiums, arenas, waterways, etc.), infrastructures, and socio-technical systems generally, which the actor has control over or access to and uses in her choices, action, interactions, and outputs. Included here are access to location(s)/appropriate situations for key activities; the base is likely to include tools and technologies for control and sanctioning activities. The resource base may be either self-mobilized or provided by an encompassing organization, e.g. a corporation or political party in relation to its purposes, activities, and particular procedures. Thus, some or all of an actor's resource base may be controlled by a collective (in practice by its leadership or collective decision). 
Essential materials and technologies for a given decision may be available to the decision-maker to varying degrees. A powerful agent has, or is likely to have, greater access to essential resources than resource poor or marginal agents in an organization or community. Thus, even highly creative persons or groups may not be in a position to try or to realize their projects and innovative ideas.

\subsection{Multiple Values, Role Contradictions and Moral Dilemmas}

The role of norms and institutions in directing and regulation a major part of social action and interaction has been stressed by Burns and Flam [47], Elster [34] [35], and Harre, [42], among many others. Elster ([34] [35]) pointed out the differences in the mechanisms of normatively and instrumentally motivated behavior; and the extreme non-rational behavior that norms may generate: For instance, the many sacrifices that parents make for their children; or, the notion of cutting one's losses is alien to the relentless pursuer of revenge ([35]). The conclusion was clear cut in his and others' work: RCT lacks the language and conceptual framework to deal systematically with norms and normative regulated behavior.

Most human action raises ethical issues. But what is considered to be moral in choices that affect human conditions, persons or groups? What moral assumptions, often implicit, are involved in judgment processes and actions? What moral dilemmas arise in the particular roles social actors play vis-a-vis one another? How do they try to deal with these or to resolve them?

At the core of a social embeddeednness approach are concepts such as norms, values and judgment processes, enabling one to identify and analyze actors' orientations about right and wrong and good and bad in particular choice situations. In contrast, rational choice (and game theories) provide little or no analytical capability to address such matters, in large part because they lack a language and conceptual tools to apply to social values, norms, value predicaments and conflicts, and their resolution. The utilitarian foundations of RCT are simply all too constraining.

Most discussions on ethical issues assume some form of moral agency, but one is all too often not informed about the different social contexts — cultural frames, social relationships and roles-which are responsible for the formation of this agency. Thus, roles in market and administrative settings entail differing normative guidelines, directives, and constraints. In market settings, it is appropriate for an actor to make her own calculations and to pursue her own interests - within certain limits of course. In an administrative setting, one's role as a subordinate entails the norm to carry out the policies, regulations, and directives of an authority. Of course, there are limits to the realization or implementation of roles in such settings. When one follows the logic of the market to an extreme, one becomes a ruthless "exploiter" of others or a "bandit." Or following the logic of a bureaucratic role to an extreme makes one into the "bureaucratic personality," "heartless" and also often ineffective. In both of these cases, the formal or institutionalized morality is constituted in social roles and group functioning. Of course, in practice, humans as moral agents often take an active part in the interpretation and adaptation of their moral positions and moral obligations in the context of market, administrative or other social settings such as family and community.

A broader analysis of ethical processes should and can take into account the particularities of social dimensions. Much social action—including the judgments underlying specific strategic acts—is role based. In general, social activities are patterned on the basis of the different roles humans play in different social contexts and social systems. Human beings in their various roles are recognized as social agents with particular moral orientations or sentiments as well as obligations. Thus, one examines how different roles and their institutional and network contexts operate as sources of moral agency.

Social actors are often in situations where more than one role (and value complex) applies which give rise to moral dilemmas or conflicts. One can consider Sophocles' play Antigone as an illustration of the difficulty of dealing with multiple moralities associated with her different roles ([48]). In the play, Antigone chooses to obey her familial duties - to bury her brother's corpse in opposition to the Monarch's law (King Creon's), believing it a sacred duty, superior to all human laws, to bury one's kin. Her brother Polynices had rebelled against the king, but was defeated and therefore treated as an enemy of war: his body was to be left unburied, and therefore his soul would wander through eternity in sorrow and anxiety. Antigone is condemned to death for her attempt and is buried alive in the vault of the Ladbacidae where she hanged herself. Antigone's conflict was a conflict of moral codes and consequently of duties. Both her role as sister of Polynices and her role as a representative of the Athenian ruling house (she as the daughter of Oedipus and the daughter in law of the ruler, Creon) put her in the dilemma of disobeying either her familial duties or her duties toward the law. 
Table 1. Rational choice theory compared to reformed choice theory with extensions.

\begin{tabular}{|c|c|c|}
\hline & Rational choice theory & Extensions \\
\hline Context & Simple material constraints and opportunities. & $\begin{array}{l}\text { Complex, dynamic contexts of culture and institutions } \\
\text { (rule regimes) as well as technologies; Material constraints } \\
\text { and opportunities, and psychological and cognitive factors. }\end{array}$ \\
\hline Actor & $\begin{array}{l}\text { Radical decontextualization. } \\
\text { The atomistic, super-rational, self-interested } \\
\text { individual outside of society and } \\
\text { social relationships. }\end{array}$ & $\begin{array}{l}\text { Emphasis on the social character of actors, their social and } \\
\text { psychological embeddedness. Actors are engaged in } \\
\text { multiple roles and social relations and are } \\
\text { creative/destructive/transformative agents who, among } \\
\text { other things, may deviate from institutionalized principles } \\
\text { of action, norms and situational constraints and, in some } \\
\text { instances, transform the situation into one with new } \\
\text { conditions, new norms, and new action } \\
\text { opportunities and payoffs. }\end{array}$ \\
\hline $\begin{array}{l}\text { Principle of } \\
\text { action }\end{array}$ & $\begin{array}{l}\text { Metaphysical universalism: a single universal } \\
\text { principle of action, the maximization of utility, } \\
\text { that is, rational choice, at the same time lacking } \\
\text { innovative, creative, and transformative } \\
\text { capabilities. The principle is applied } \\
\text { universally, abstracting from all cultural } \\
\text { and social contexts, civilizations, historical } \\
\text { epochs, institutional spheres, social } \\
\text { relationships, and cultural forms, etc. }\end{array}$ & $\begin{array}{l}\text { Context dependent action. The social rules, norms, roles, } \\
\text { institutional arrangements, groups, networks and } \\
\text { organizations define context dependent action situations, } \\
\text { guidelines and algorithms including possibly variants of } \\
\text { instrumental rationality which may or may not be } \\
\text { combined with other values; multi-value conditions, } \\
\text { dilemmas, and contradictions are generated. }\end{array}$ \\
\hline $\begin{array}{l}\text { Motivation and } \\
\text { values }\end{array}$ & $\begin{array}{l}\text { Defined by a utility function or preferences } \\
\text { which derive exogenously from the choice } \\
\text { situation. Preferences are assumed to be } \\
\text { complete, fully ordered and consistent, } \\
\text { as well as stable over time and space. }\end{array}$ & $\begin{array}{l}\text { An actor's context dependent values and evaluative } \\
\text { structures provide the basis of motivation and action in a } \\
\text { given situation. They derive from the institutional setup, } \\
\text { social relationships, and particular norms and roles. }\end{array}$ \\
\hline $\begin{array}{l}\text { Sacrality or deep } \\
\text { values and morality }\end{array}$ & $\begin{array}{l}\text { All preferences are of a single class. } \\
\text { "Everything is negotiable. Actors have no } \\
\text { particular morality, that is there are no } \\
\text { transcendental preferences which trump } \\
\text { ordinary preferences. }\end{array}$ & $\begin{array}{l}\text { Some values belong to a sacred core grounded in } \\
\text { individual and/or group identity, the institution or } \\
\text { organization. "Not everything is negotiable.” Actors as } \\
\text { social beings are moral agents and to a great extent try to } \\
\text { act according to core norms and values, but make deviant } \\
\text { choices when they feel justified or "coerced.” }\end{array}$ \\
\hline Norms & $\begin{array}{l}\text { A norm applies only if the self-interested } \\
\text { actor choses to comply with it because } \\
\text { it is in her self-interest. }\end{array}$ & $\begin{array}{l}\text { In many instances, actors are committed to following the } \\
\text { norms (multiple factors including self-interest). }\end{array}$ \\
\hline Institutions & $\begin{array}{l}\text { Actor only accept institutional roles and norms } \\
\text { if it is the actor's self-interest. Consequently, } \\
\text { institutions emerge in a moment, spontaneously. }\end{array}$ & $\begin{array}{l}\text { In many instances, actors are committed to following } \\
\text { norms and institutionalized rules (based on multiple } \\
\text { factors including self-interest). Actors may try to bring } \\
\text { about a change in an institution because it conflicts } \\
\text { with a key norm or value, or fails to operate } \\
\text { properly or effectively. }\end{array}$ \\
\hline $\begin{array}{l}\text { Cognitive } \\
\text { framework }\end{array}$ & $\begin{array}{l}\text { A cognitive framework incorporates complete } \\
\text { information and full knowledge of the actor's } \\
\text { choice situation, her action alternatives and their } \\
\text { outcomes and eventual payoffs. On the other } \\
\text { hand, there is little or no cultural or institutional } \\
\text { knowledge (why should there be if an actor and } \\
\text { her situation are outside society). }\end{array}$ & $\begin{array}{l}\text { An actor has incomplete information about the situation, } \\
\text { her action alternatives, and possible outcomes, and, as a } \\
\text { result, unintended consequences of choices. On the other } \\
\text { hand, a socialized actor has substantial cultural and } \\
\text { institutional knowledge about the situation, the } \\
\text { institutional arrangements, her role(s), and social } \\
\text { relationships and even in some instances how to } \\
\text { bring about change in norms and institutions. }\end{array}$ \\
\hline $\begin{array}{l}\text { Cognitive-evaluative } \\
\text { capabilities }\end{array}$ & $\begin{array}{l}\text { Possessing super-capability of cognition, } \\
\text { calculation and choice according to the } \\
\text { fixed axiom of rational choice. } \\
\text { No Antigone dilemma or Hamlet } \\
\text { syndrome of blocked choice. }\end{array}$ & $\begin{array}{l}\text { Bounded cognitive, evaluation, and choice capabilities. } \\
\text { Contradiction, incoherence and dilemmas arise because } \\
\text { of multiple values and norms which do not typically’ fit } \\
\text { together neatly in any given situation. Antigone type } \\
\text { dilemmas and Hamlet syndromes are to be expected. }\end{array}$ \\
\hline
\end{tabular}


In the play Sophocles pointed at one central issue that can be understood as a dilemma that occupied the mind of many Greek thinkers at that time and still remains a central issue in Western thought and policy: the conflict of public rights versus private (including individual rights). In the play the conflict arises when familial (and also individual morality, that of Antigone), clashes with the system of laws and authority represented by King Creon. Sophocles raised questions about the legality of the law and about the extent to which societal or state rights can or should prevail over individual rights. And how should a morally responsible individual behave in the face of social institutions that do not support, but rather deny, individual responsibility and thus may be said to conflict with human nature itself? Such dilemmas and the social conditions and judgment processes that generate them can be specified and analyzed within an extended choice framework, and contrasts to conventional rational choice theory (and classical game theory) with their grounding in an utilitarian theory of value and the absence of conceptual tools to deal with multiple values, value conflicts and moral dilemmas. Burns [4] [40] [45] examine actors' reasoning processes relating to such conflicts and dilemmas and their attempts at practical resolution, including the transformation of their interaction situations, roles, and role relationships.

\section{Conclusions}

A number of social scientists (Coleman, Elster, Kahneman \& Tversky, Sen, Simon, Thaler and Sunstein, among many others), drawing on psychology and the cognitive sciences along with anthropology and sociology, have brought greater realism, empirical relevance, and moral direction to the rational choice approach. These developments emerged as challenges to conventional rational choice theory and mainstream economics. The work demonstrated that rational economic man, the all-seeing, all knowing figure on whose shoulders much of contemporary economics has been constructed, was a largely fictional character. Faced with even simple sets of options to pick from, human beings make decisions that are inconsistent, suboptimal, and, sometimes, plain stupid, because of cognitive or judgmental limitations, miscalculations, or simply emotional impulses. They often rely on misleading rules of thumb and leap to inappropriate conclusions and actions. Moreover, they are heavily influenced by how the choices are presented to them and, sometimes, by completely false or irrelevant information ([6]). The parallels and contrasts between conventional RCT and the emerging extensions and revisions are presented in Table 1 with reference to key social science dimensions.

The many recent contributions to choice theory in different areas, as suggested above, made for much fragmentation of choice theory. As of yet, unfortunately, there is no integrated approach to displace the core RCT approach. Some in the name of methodological pluralism find advantages in the development of a multitude of diverse models, a very different world from the one where RCT reigned supreme.

\section{References}

[1] Arrow, K.J. (1951) Alternative Approaches to the Theory of Choice in Risk-Taking Situations. Econometrica, 19, 404437. http://dx.doi.org/10.2307/1907465

[2] Becker, G. (1976) The Economic Approach to Human Behavior. University of Chicago Press, Chicago.

[3] Boudon, R. (1981) The Logic of Social Action. Routledge, London.

[4] Bums, T. (1990) Models of Social and Market Exchange: Toward a Sociological Theory of Games and Social Behavior. In: Calhoun, C., Meyer, M.W. and Scott, W.R., Eds., Structures of Power and Constraints, Papers in Honor of Peter M. Blau, Cambridge University Press, Cambridge.

[5] Burns, T.R. (1994) Two Conceptions of Human Agency: Rational Choice Theory and the Social Theory of Action. In: Sztompka, P., Ed., Agency and Structure. Reorienting Social Theory, Gordon and Breach.

[6] Cassidy, J. (2008) Economics: Which Way for Obama? Review of R.H. Thaler and C.R. Sunstein, New York Review of Books June 12, 2008, 30-34.

[7] Chapman, B. (1998) Law Games: Defeasible Rules and Revisable Rationality. Law and Philosophy, 17, 443-480. http://dx.doi.org/10.2307/3505089

[8] Chapman, B. (1998) More Easily Done than Said: Rules, Reasons and Rational Social Choice. Oxford Journal of Legal Studies, 18, 293-329. http://dx.doi.org/10.1093/ojls/18.2.293

[9] Chater, N. (2015) Can Cognitive Science Create a Cognitive Economics? Cognition, 135, 52-55. http://dx.doi.org/10.1016/j.cognition.2014.10.015

[10] Coleman, J. (1990) Foundations of Social Theory. Belknap Press of Harvard University Press, Cambridge.

[11] Hamburger, H. (1979) Games as Models of Social Phenomenon. Freeman, San Francisco. 
[12] Hedstrom, P. (2005) Dissecting the Social: On the Principles of Analytical Sociology. Cambridge University Press, Cambridge. http://dx.doi.org/10.1017/CBO9780511488801

[13] Jackson, P.C. (1974) Introduction to Artificial Intelligence. Petrocelli and Charles, New York.

[14] Luce, R.D. and Raiffa, H. (1957) Games and Decisions. Wiley, New York.

[15] Luce, R.D. (1959) Individual Choice Behavior: A Theoretical Analysis. Wiley, New York.

[16] Renn, O., Jaeger, C., Rosa, E. and Webler, T. (2000) The Rational Actor Paradigm in Risk Theories: Analysis and Critique. In: Cohen, M.J., Ed., Risk in the Modern Age. Social Theory, Science and Environmental Decision-Making, Palgrave, Houndmills, 35-61.

[17] Burns, T.R., Baumgartner, T. and DeVille P. (1985) Man, Decision and Society. Gordon and Breach, London.

[18] Green, D.P. and Shapiro I. (1994) Pathologies of Rational Choice Theory: A Critique of Applications in Political Science. Yale University Press, New Haven.

[19] Harsanyi, J.C. (1977) Rational Behavior and Bargaining Equilibrium in Games and Social Situations. Cambridge University Press, Cambridge. http://dx.doi.org/10.1017/CBO9780511571756

[20] Hollis, M. (1987) The Cunning of Reason. Cambridge University Press, Cambridge.

[21] Hogardi, R. and Reder, M. (1987) Rational Choice: The Contrast between Economics and Psychology. University of Chicago Press, Chicago.

[22] Kahneman, D. and Tversky, D. (1979) A Prospect Theory: An Analysis of Decision under Risk. Econometrica, 47, 263-291. http://dx.doi.org/10.2307/1914185

[23] Kahneman, D. and Miller, D. (1986) Norm theory: Comparing Reality to Its Alternatives. Psychological Review, 93, 136-153. http://dx.doi.org/10.1037/0033-295X.93.2.136

[24] Kahneman, D., Slovic, P. and Tversky, A., Eds. (1982) Judgments under Uncertainty: Heuristics and Biases. Cambridge University Press, Cambridge. http://dx.doi.org/10.1017/CBO9780511809477

[25] March, J.G. and Simon, H.A. (1958) Organizations. Willey, New York.

[26] Sen, A.K. (1977) Rational Fools: A Critique of the Behavioral Foundations of Economic Theory. Philosophy and Public Affairs, 6, 317-344.

[27] Sen, A.K. (1989) Choice, Welfare, and Measurement. Basil Blackwell, Oxford.

[28] Sen, A.K. (2008) Rational Behavior. In: The New Palgrave: A Dictionary of Economics, 2nd Edition, MacMillan, London, 68-76.

[29] Scharpf, F.W. (1997) Games Real Actors Play: Actor-Centered Institutionalism in Policy Research. Westview Press, Boulder.

[30] Simon, H.A. (1957) Models of Man. Wiley, New York.

[31] Simon, H.A. (1977) Models of Discovery and Other Topics in the Methods of Science. Reidel, Dordrecht.

[32] Simon, H.A. (1967) Motivational and Emotional Controls of Cognition. Psychological Review, 74, $29-39$. http://dx.doi.org/10.1037/h0024127

[33] Allais, M. and Hagen, O., Eds. (1979) Expected Utility Hypotheses and the Allais Paradox. Springer, Dordrecht, Holland. http://dx.doi.org/10.1007/978-94-015-7629-1

[34] Elster, J. (1989) Nuts and Bolts for the Social Sciences. Cambridge University Press, Cambridge. http://dx.doi.org/10.1017/CBO9780511812255

[35] Elster, J. (1989) Cement of Society. Cambridge University Press, Cambridge. http://dx.doi.org/10.1017/CBO9780511624995

[36] Granovetter, M. (1985) Economic Action and Social Structure. American Journal of Sociology, 50, 384-510.

[37] Burns, T.R. and Hall, P.M. (2012) The Meta-Power Paradigm: Impacts and Transformations of Agents, Institutions, and Social Systems. Peter Lang, Frankfurt am Main, New York, Oxford.

[38] Giddens, A. (1984) The Constitution of Society. Polity Press, Oxford.

[39] Thaler, R.H. and Sunstein, C.R. (2008) Nudge: Improving Decisions about Health, Wealth, and Happiness. Yale University Press, New Haven.

[40] Burns, T.R. and Roszkowska, E. (2008) The Social Theory of Choice: From Simon and Kahneman-Tversky to GGT Modelling of Socially Contextualized Decision Situations. OPTIMUM Economic Studies, 3, 3-44.

[41] Elster, J. (1993) Some Unresolved Problems in the Theory of Rational Behavior. Acta Sociologica, 36, 179-190. http://dx.doi.org/10.1177/000169939303600303

[42] Harré, R. (1979) Social Being. Basil Blackwell, Oxford. 
[43] Hodgson, G.M. (1986) Behind Methodological Individualism. Cambridge Journal of Economics, 10, 211-224.

[44] Hodgson, G.M. (1989) Institutional Economic Theory: The Old versus the New. Review of Political Economy, 1, 249269. http://dx.doi.org/10.1080/09538258900000021

[45] Burns, T.R. and Roszkowska, E. (2007) Multi-Value Decision-Making and Games: The Perspective of Generalized Game Theory on Social and Psychological Complexity, Contradiction, and Equilibrium. In: Shi, Y., Ed., Advances in Multiple Criteria Decision Making and Human System Management: Knowledge and Wisdom, IOS Press, Amsterdam, 75-107.

[46] Burns, T.R., Machado, N. and Corte, U. (2015) The Sociology of Creativity: Part I: Theory. Human Systems Management, 34, 179-199. http://dx.doi.org/10.3233/HSM-150839

[47] Burns, T.R. and Flam H. (1987) The Shaping of Social Organization: Social Rule System Theory with Applications. Sage Publications, London.

[48] Machado, N. (1998) Using the Bodies of the Dead. Ashgate, London. 